\title{
Pumping power station ash as a high concentration slurry
}

\author{
T.F. Bunn Centre for Bulk Solids and Particulate Technologies and TUNRA Bulk Solids, The University of \\ Newcastle, Australia
}

M.G. Jones Centre for Bulk Solids and Particulate Technologies and TUNRA Bulk Solids, The University of Newcastle, Australia

C.A. Wheeler Centre for Bulk Solids and Particulate Technologies and TUNRA Bulk Solids, The University of Newcastle, Australia

\begin{abstract}
Determining the pumping characteristics of a full scale power station ash disposal system is fraught with difficulties. This paper examines the pumping characterises of high concentration slurry comprising of a mixture of a power station ash and process water as determined using a rotary viscometer and small scale pumping test rig.
\end{abstract}

\section{Introduction}

The pumping of power station ashes as high concentration slurry has become common place in Australian black coal fired power stations (Ward et al., 1999). The fly ash is collected from either the precipitator or fabric filter hopper and is conveyed either by chain scraper and bucket elevator or pneumatically to a fly ash silo. The bottom ash is collected by either a wet or dry scraper conveyor. The bottom ash that is collected from a wet scraper conveyor is transferred to a bottom ash silo after being crushed. Alternatively the bottom ash could be collected by a dry scraper conveyor, crush and pneumatically conveyed directly to the fly ash silo. The fly ash, bottom ash and water are then mixed together in a pug mill and transferred to a mixing tank before being pumped to a disposal site using high pressure positive displacement pumps. The pipeline to the disposal site is usually constructed of steel and is either welded or joined with high pressure couplings. At some disposal sites polyethylene pipe is used to transfer the slurry to multi disposal points.

This study looked at the comparison of results of shearing high concentration fly ash slurry in a rotary viscometer with the pumping of slurry consisting of fly ash and bottom ash using a $50 \mathrm{~mm}$ pilot pumping plant. Initially the rotary viscometer study was undertaken followed a couple of months later by the pumping trial. The testing was undertaken with the view to determine the pressure drop characteristics of pumping a mixture of fly ash and bottom ash use a twin cylinder piston pump fitted with ' $\mathrm{S}$ ' transfer tube output system in a $150 \mathrm{~mm}$ pipeline with a flow rate of $100 \mathrm{~m}^{3} \mathrm{~h}^{-1}$ at a maximum pressure of $6 \mathrm{MPa}$ to disposal from the power station. To reflect the pulse pressure characteristics of the piston pumps a hose pump was used in the pilot plant.

Agreement between shear rate (measured using a rotary viscometer) and the pseudo shear rate (8V/D) in a pipeline was noted by (Bunn, 1991) which conducting pumping trial using a rotary ram pump. The trials consisted of pumping fly ash slurries from three different Hunter Valley power stations with the rotary ram pump and simultaneously shearing the slurries in a rotary viscometer. Only the fly ash slurry from Bayswater power station showed agreement between the shear rate (measured by a rotary viscometer) and the pseudo shear rate measured in the pipeline. In the case of the other fly ashes the rotary viscometer measurements underestimated the shear stress in the range of 50 to $400 \%$ depending of the source of the fly ash and the concentration by weight $\left(\mathrm{C}_{\mathrm{w}}\right)$, of the slurry, the higher the $\mathrm{C}_{\mathrm{w}}$ the greater the underestimation. This led to the assumption that the fly ash slurries from Bayswater power station were homogeneous whereas the slurries from the other power stations were heterogeneous. 


\section{Methodology}

Twenty-five litre containers were used to collect samples of fly ash, bottom ash and service from an Australian black coal power station. It was assumed that the samples were typical of the station ash and process.

A sample of fly ash was sent for SEM analysis. Elemental and atomic analysis are shown in Tables 1 and 2. SEM photographs are seen in Figures 1 and 2.

Table 1 Elemental analysis of fly ash

\begin{tabular}{llllllllll}
\hline & \multicolumn{8}{c}{ Elemental Analysis \% } \\
& $\mathbf{N a}$ & $\mathbf{M g}$ & $\mathbf{A l}$ & $\mathbf{S i}$ & $\mathbf{S}$ & $\mathbf{K}$ & $\mathbf{C a}$ & $\mathbf{T i}$ & $\mathbf{F e}$ \\
\hline 1 & 0.98 & 0.36 & 33.03 & 58.62 & 1.71 & 0.94 & 2.47 & 1.58 & 1.02 \\
2 & 0.87 & 0.43 & 29.32 & 53.14 & 1.48 & 1.29 & 4.28 & 3.21 & 5.99 \\
3 & 0.87 & 0.37 & 29.29 & 52.48 & 1.17 & 1.58 & 4.26 & 3.22 & 7.5 \\
4 & 0.93 & 0.36 & 29.23 & 53.02 & 1.68 & 1.14 & 4.25 & 2.98 & 6.41 \\
\hline
\end{tabular}

Table 2 Atomic analysis of fly ash

\begin{tabular}{llllllllll}
\hline & \multicolumn{10}{c}{ Atomic Analysis \% } \\
& $\mathbf{N a}$ & $\mathbf{M g}$ & $\mathbf{A l}$ & $\mathbf{S i}$ & $\mathbf{S}$ & $\mathbf{K}$ & $\mathbf{C a}$ & $\mathbf{T i}$ & $\mathbf{F e}$ \\
\hline 1 & 1.21 & 0.42 & 34.68 & 59.13 & 1.51 & 0.68 & 1.74 & 0.94 & 0.52 \\
2 & 1.11 & 0.52 & 32.01 & 55.74 & 1.36 & 0.97 & 3.15 & 1.98 & 3.16 \\
3 & 1.12 & 0.45 & 32.3 & 55.59 & 1.09 & 1.2 & 3.16 & 2 & 4 \\
4 & 1.19 & 0.44 & 31.94 & 55.67 & 1.54 & 0.86 & 3.12 & 1.84 & 3.39 \\
\hline
\end{tabular}

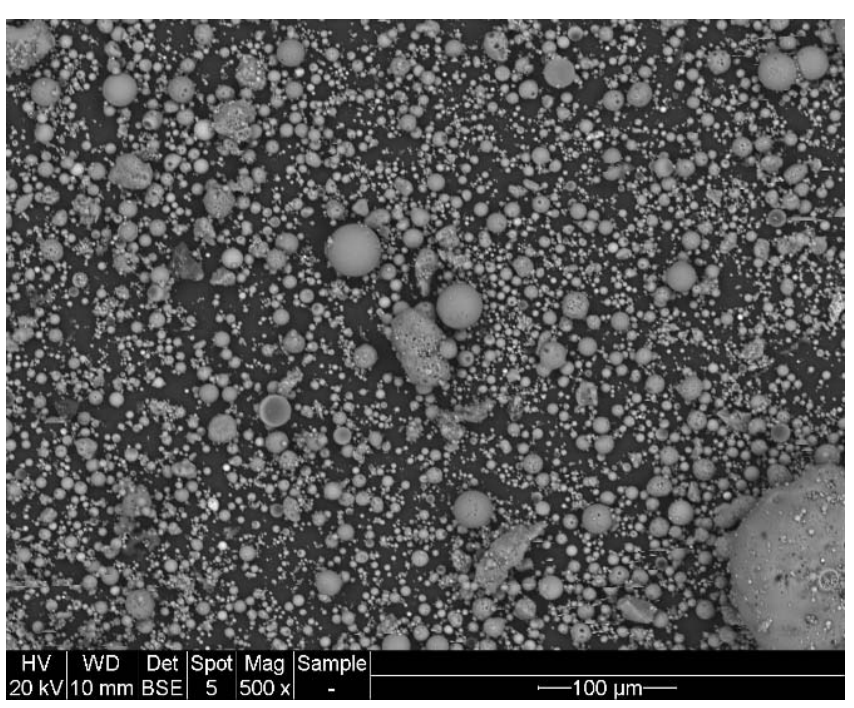

Figure 1 SEM photograph of fly ash 


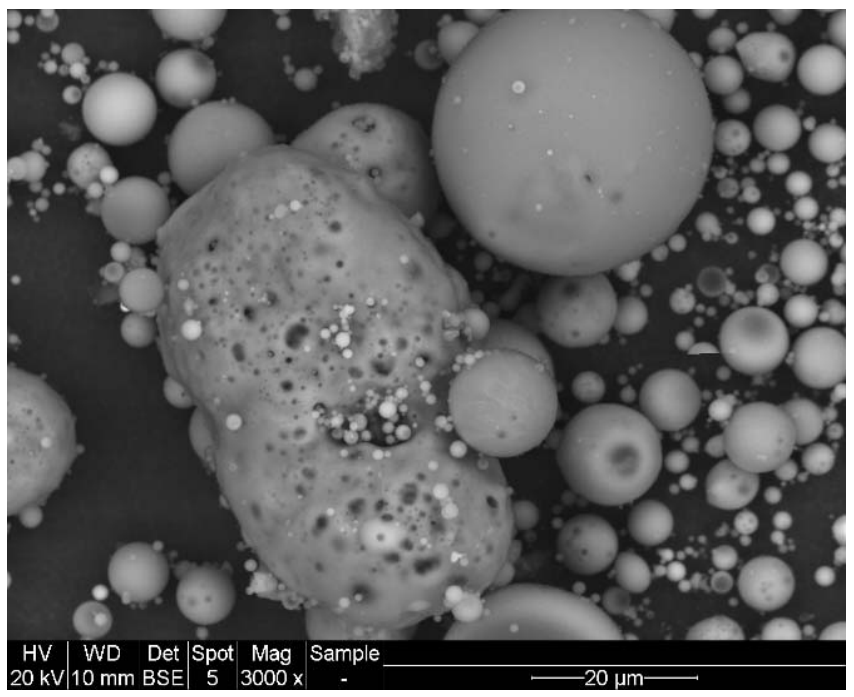

\section{Figure 2 SEM photograph of fly ash}

The particle size distributions (PSD) were of the fly ash samples was determined using a laser diffraction technique (Malvern Particle Size Analyser). A $2 \mathrm{~kg}$ sample of bottom ash was then dried and then sieved. This PSD of the fly ash and bottom ash is shown in Figure 3 . The concentration by weight $\left(\mathrm{C}_{\mathrm{w}}\right)$ of the bottom ash, as received from the power station, was $49 \%$.

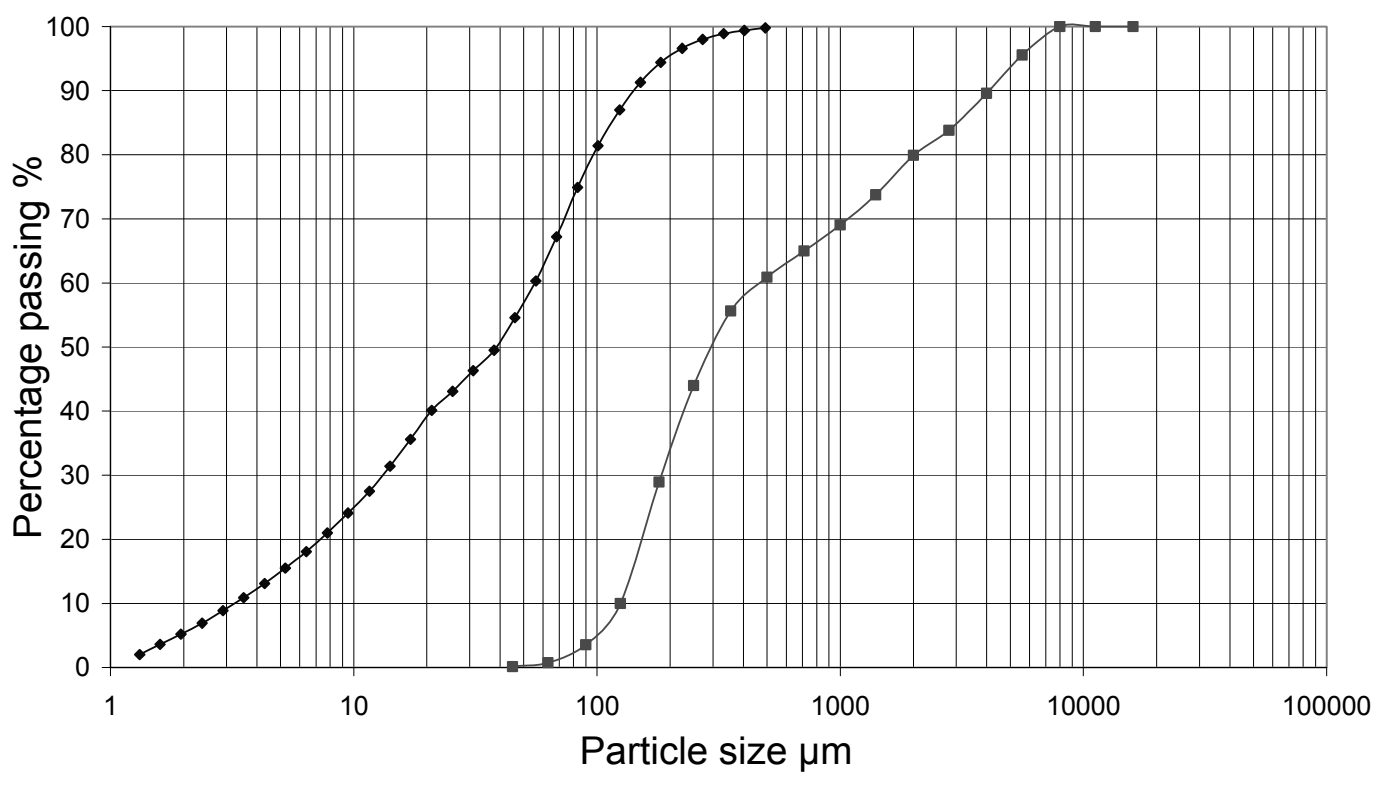

$\rightarrow$ Fly ash $\rightarrow$ Bottom ash

\section{Figure 3 Particle size distribution of fly ash}

The solids density of the fly ash and bottom ash from several different buckets was tested with a Micromeritics AccuPyc Pycnmoter 1330. The data in the Table 3 is taken directly from the measuring instrument. 
Table 3 Density of fly ash and bottom ash

\begin{tabular}{lllllll}
\hline Test & Fly Ash 1 & Fly Ash 2 & Fly Ash 3 & Fly Ash 4 & Bottom Ash A & Bottom Ash B \\
\hline 1 & 1.7680 & 1.7980 & 1.8488 & 1.8407 & 1.8633 & 1.8527 \\
2 & 1.7673 & 1.7977 & 1.8485 & 1.8402 & 1.8671 & 1.8540 \\
3 & 1.7671 & 1.7974 & 1.8462 & 1.8394 & 1.8678 & 1.8539 \\
Average & 1.7675 & 1.7977 & 1.8478 & 1.8401 & 1.8660 & 1.8535 \\
\hline
\end{tabular}

\subsection{Rotary viscometry}

Rheology tests were conducted using a Contraves Rotary Viscometer. Figure 4 is a photograph of the rotary viscometer. Water was progressively added to $1.75 \mathrm{~kg}$ of dry fly ash in a $2 \mathrm{~L}$ container. A vertical stirrer was used mix the slurry until a consistency of thick honey was obtained. This is shown in Figure 5. A sample of approximately $200 \mathrm{~g}$ of the slurry was the placed in the rotary viscometer cup for shearing. More water was added to the container to reduce the solids concentration by weight $\left(\mathrm{C}_{\mathrm{w}}\right)$ for the next test. After shearing, the slurry from the rotary viscometer cup was then placed in a Petri Dish, weighed, dried and re-weighed to determine the sample $\mathrm{C}_{\mathrm{w}}$. The slurry test was repeated several times at different $\mathrm{C}_{\mathrm{w}}$ 's.

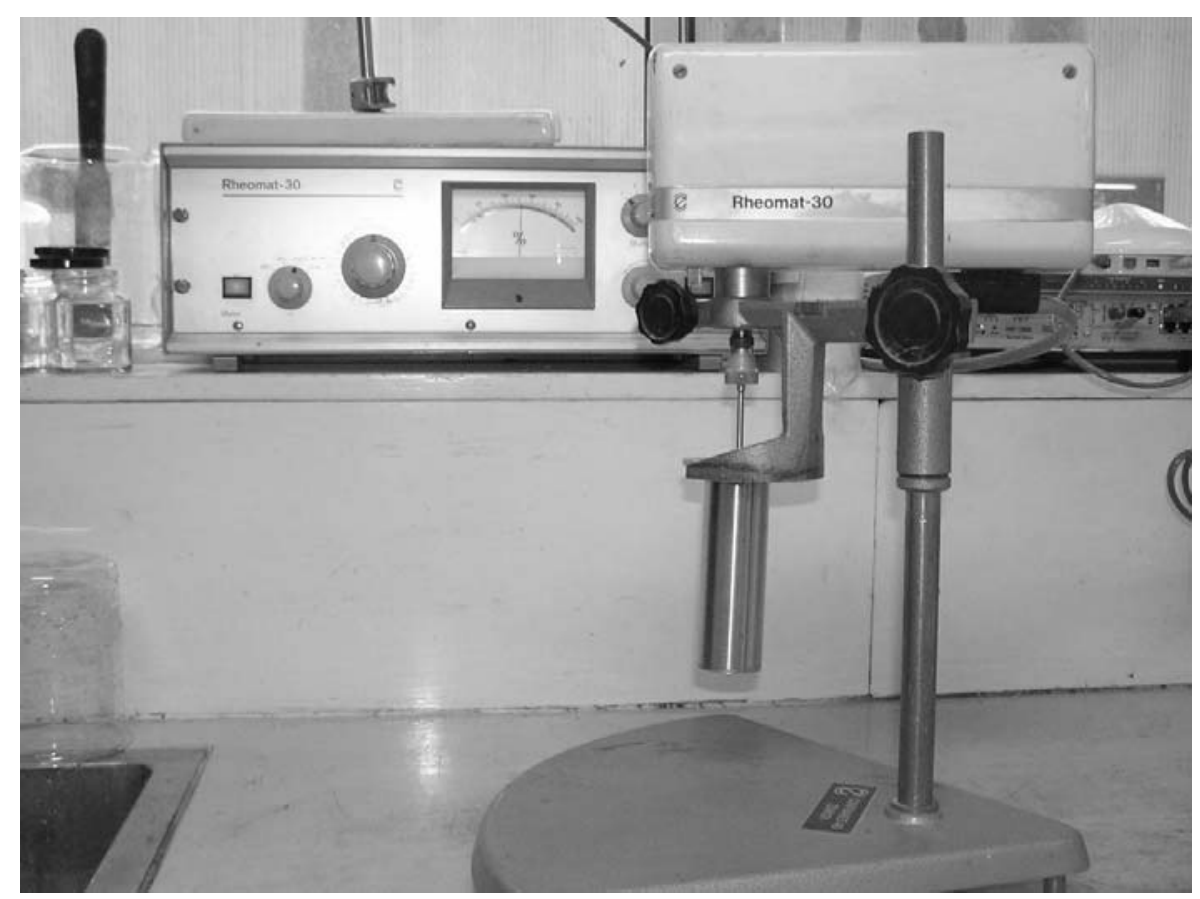

Figure 4 Contraves Rotary Viscometer used for testing 


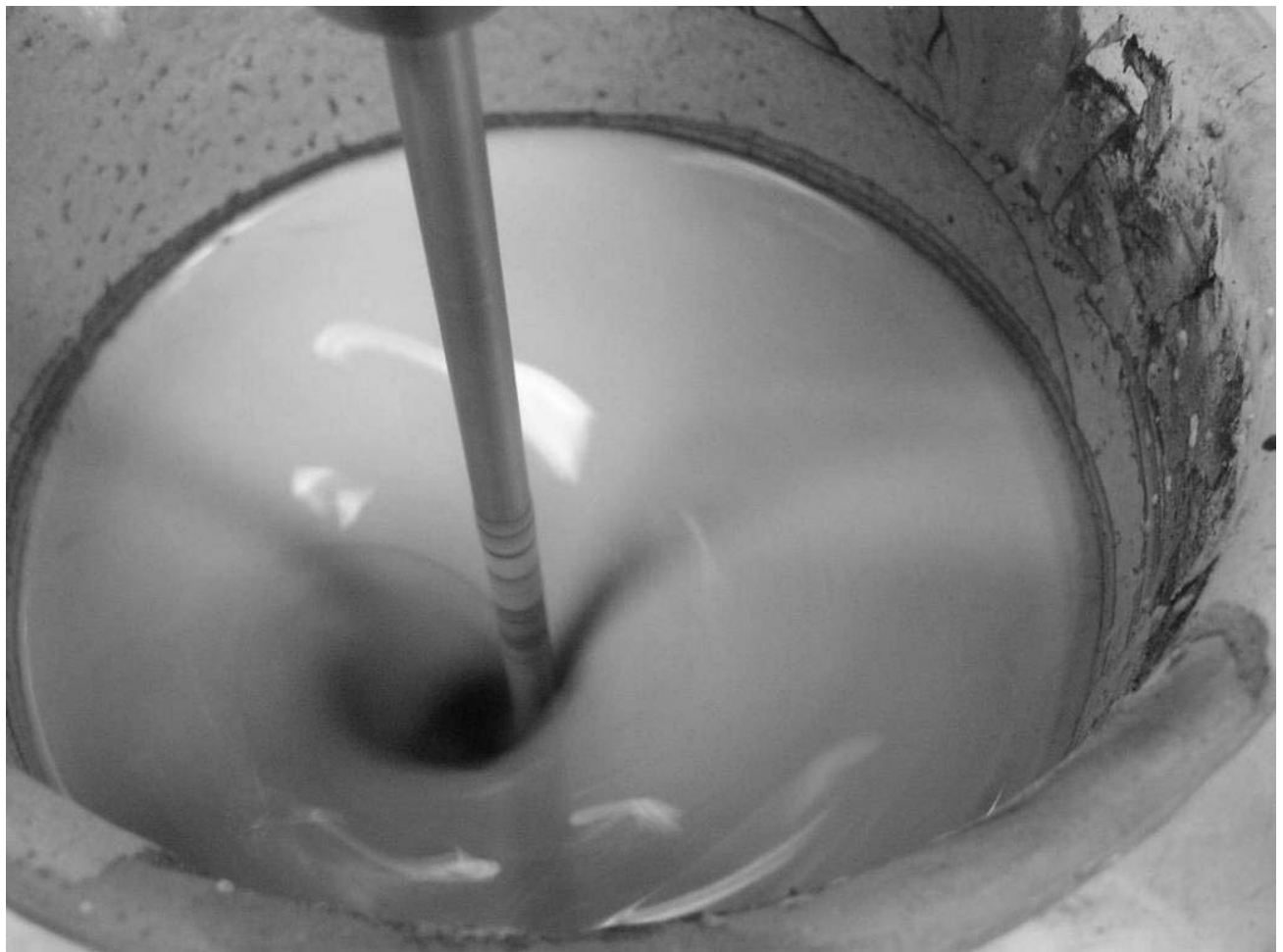

Figure 5 Mixing of fly ash slurry

\subsection{Pilot pumping plant}

A layout drawing of the pilot plant used is shown in Figure 6 and a picture of the pump is shown in Figure 7.

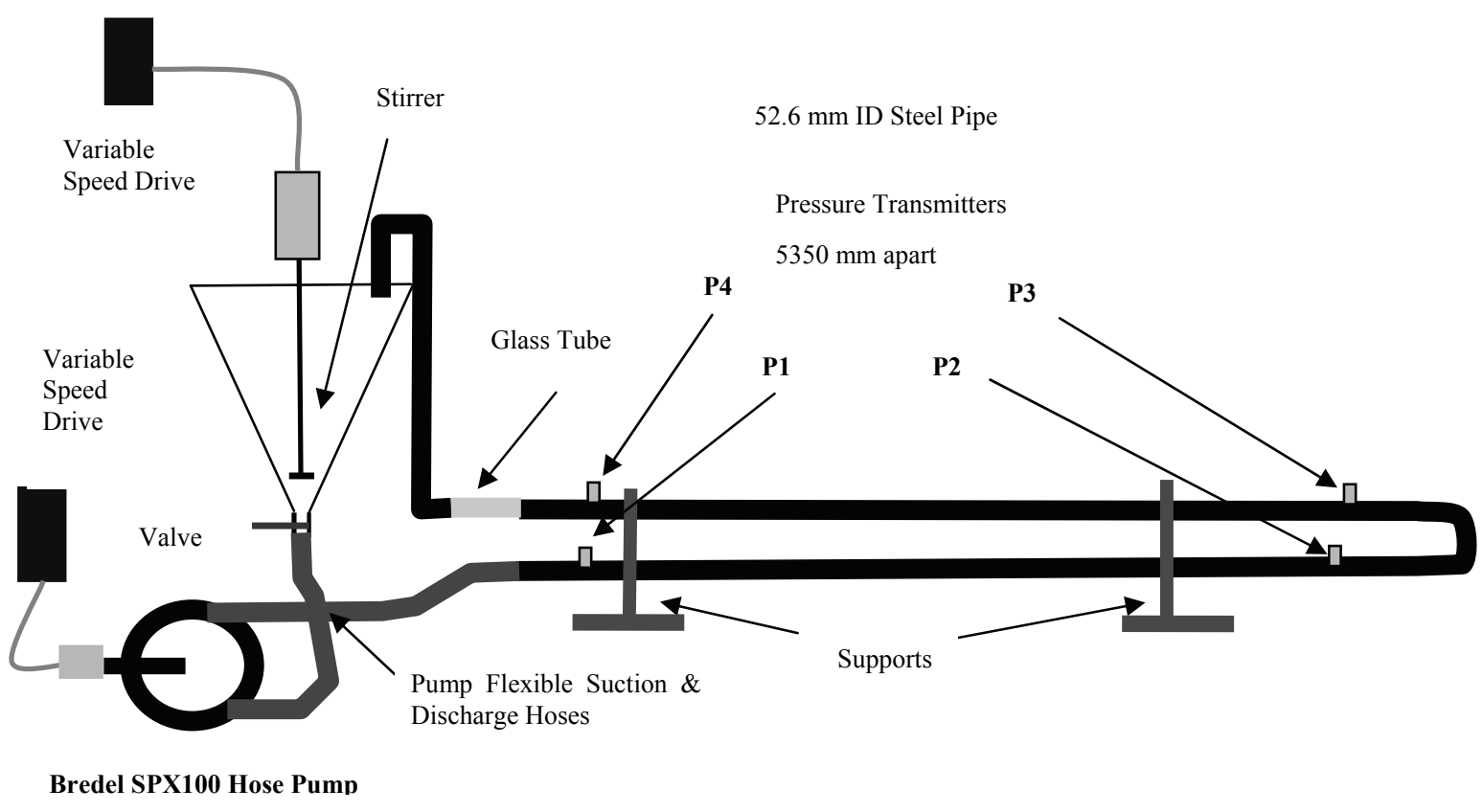

Figure 6 Diagram of the pilot pumping plant 


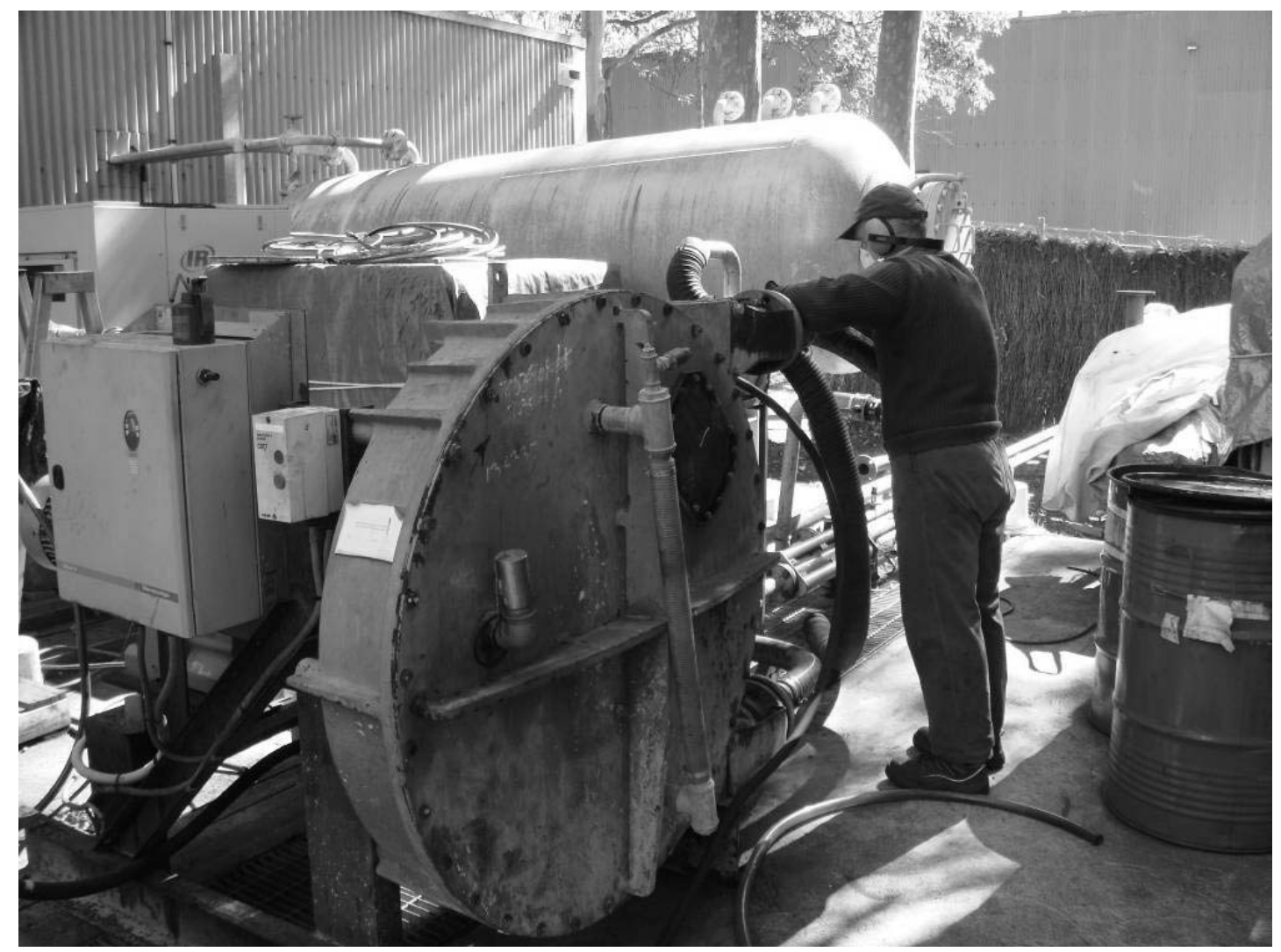

\section{Figure 7 Bredel SPX100 hose pump}

The pilot plant consisted of a variable speed Bredel SPX100 hose pump with a maximum flowrate of $24 \mathrm{~m}^{3} \mathrm{~h}^{-1}$ at a pressure of $500 \mathrm{kPa}$ and a horizontal $50 \mathrm{~mm}$ pipeline. The hose pump was calibrated using water with the classical stopwatch and bucket technique. It compared favourably with the manufacturer's performance chart. The capacity versus flow rate calibration is shown in Table 4.

Table 4 Comparison of speed versus flow for the Bredel SPX100 hose pump with water

\begin{tabular}{lll}
\hline $\begin{array}{l}\text { Potentiometer } \\
\text { Positions }\end{array}$ & $\begin{array}{l}\text { Digital } \\
\text { Readout }\end{array}$ & $\begin{array}{l}\text { Flow } \\
\mathbf{m}^{\mathbf{3}} \mathbf{h}^{-\mathbf{1}}\end{array}$ \\
\hline 1 & 5.0 & 2.2 \\
2 & 9.1 & 4 \\
3 & 13.5 & 6 \\
4 & 18 & 8 \\
5 & 25.2 & 10 \\
\hline
\end{tabular}

The pilot plant instrumentation consisted of four pressure transmitters and a pipeline temperature transmitter. A data collector and laptop computer were used to collect the data.

\subsubsection{Slurry mixing and pumping}

In modern boiler units the typical collection ratio of $85 \%$ fly ash to $15 \%$ bottom ash. Initially, pumping tests were conducted at this ratio and at different $\mathrm{C}_{\mathrm{w}}$ 's. Additional bottom ash was then added to change the ratio of $108 \mathrm{~kg}$ of fly ash, the mixture $80 \%$ fly ash and $20 \%$ bottom ash and this slurry was tested at different $\mathrm{C}_{\mathrm{w}}$ 's. 
The slurry was made up of:

- $38 \mathrm{~kg}$ of wet bottom ash (equivalent to19 $\mathrm{kg}$ dry bottom ash)

- $46 \mathrm{~kg}$ of process water.

The slurry was mixed for 20 minutes in the external mixer. This mixing is shown in Figure 8.

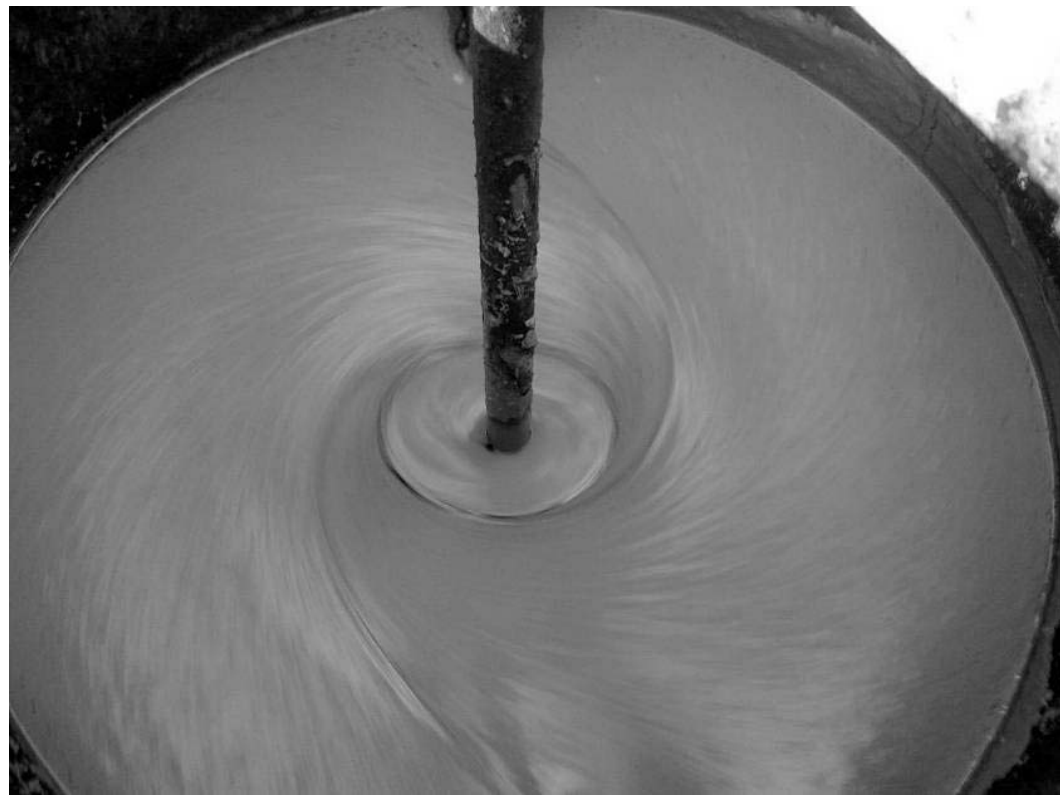

\section{Figure 8 Slurry mixing in external mixer}

Prior to pumping the pipeline and test rig hopper was filled with water, the pump started and the pipeline flushed. On completion of flushing the hopper was emptied to a level just below the hopper outlet valve and the pump and pipeline was left full of water. The hopper outlet valve was closed.

The test rig hopper electrical stirrer was started and the slurry mixed in external mixer was added to the hopper. When approximately $110 \mathrm{~L}$ of slurry $(90 \mathrm{~kg}$ of fly ash and $13.5 \mathrm{~kg}$ of bottom ash) had been added to the hopper the hopper outlet valve was opened and the hose pump was started on low flow. A temporary flexible hose was used to discharge water in the pipelined into a $200 \mathrm{~L}$ drum. When slurry appeared the hose pump was stopped and the flexible hose removed. The hose pump was restarted and set to potentiometer position 5 .

The slurry was circulated until uniform data was obtained. The data was then was recorded for 2-3 minutes. At this time a sample of the slurry was removed for $\mathrm{C}_{\mathrm{w}}$ verification. The same procedure was followed for the remaining four potentiometer positions. Slurry discharging from the pipeline and into the hopper is shown in Figures 9 and 10.

Prior to the collection of data the slurry was allowed to stabilise. Subsequent testing included:

- addition of $1 \mathrm{~kg}$ of water to decrease the $\mathrm{C}_{\mathrm{w}}$ of the slurry

- addition of another $1 \mathrm{~kg}$ of water to decrease the $\mathrm{C}_{\mathrm{w}}$ of the slurry

- addition of $13 \mathrm{~kg}$ of wet bottom ash to bring the slurry bottom ash content to $20 \%$

- addition of $1 \mathrm{~kg}$ of water to decrease the $\mathrm{C}_{\mathrm{w}}$ of the slurry.

On completion of the final pumping run the pump was stopped, the hopper was filled with water and the pipeline discharge was again diverted to the $200 \mathrm{~L}$ drum for environmental friendly disposal. 


\subsubsection{Pilot plant calculations}

The pilot plant pressure transducers with a range of 0 to $250 \mathrm{kPa}$ with an accuracy of $0.25 \% \mathrm{FSO}$. The pseudo shear rate and shear stress was calculated:

$$
\dot{\gamma}=\frac{8 v}{d}
$$

Where:

$\begin{array}{rll}\dot{\gamma} & = & \text { pseudo shear rate }\left(\mathrm{s}^{-1}\right) . \\ \mathrm{v} & = & \text { velocity }\left(\mathrm{ms}^{-1}\right) . \\ \mathrm{d} & = & \text { pipe diameter }(\mathrm{m}) .\end{array}$

$$
\tau=\frac{d D P}{4 l}
$$

Where:

$$
\begin{array}{lll}
\tau & = & \text { shear stress }(\mathrm{Pa}) \\
\mathrm{DP} & = & \text { differential pressure }(\mathrm{Pa}) \\
1 & = & \text { length }(\mathrm{m}) .
\end{array}
$$

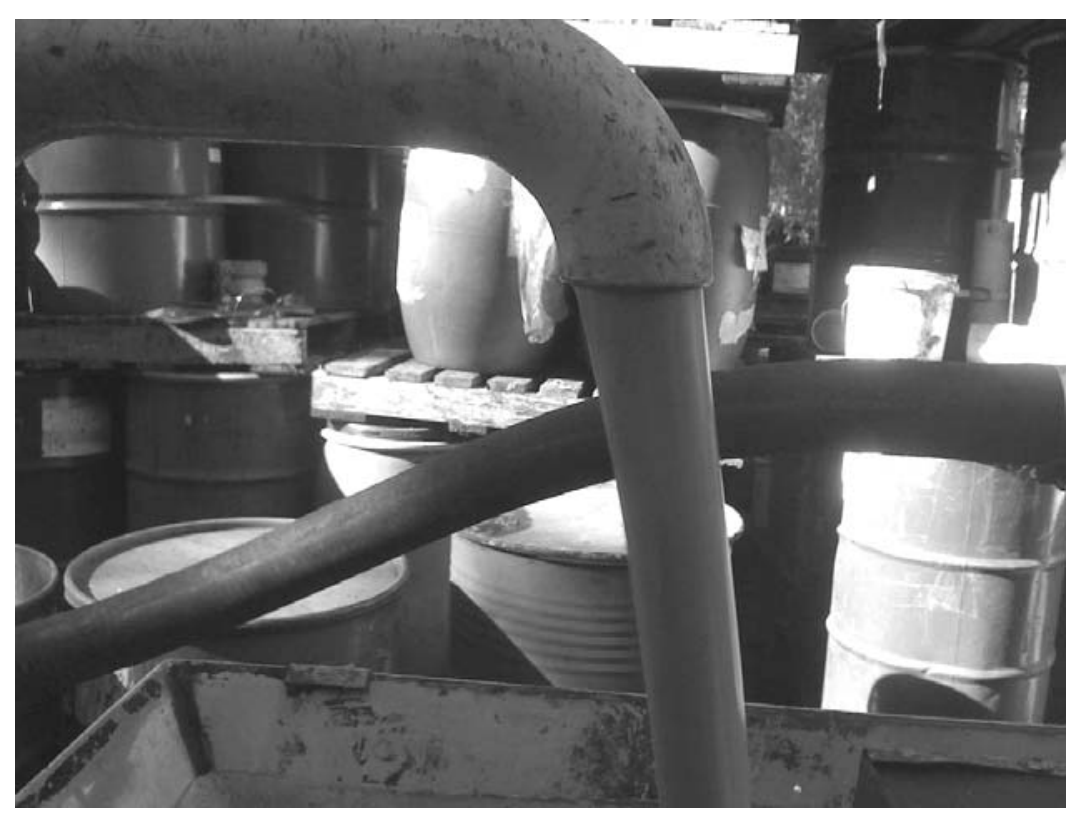

Figure 9 Slurry discharge from pilot plant pipeline 


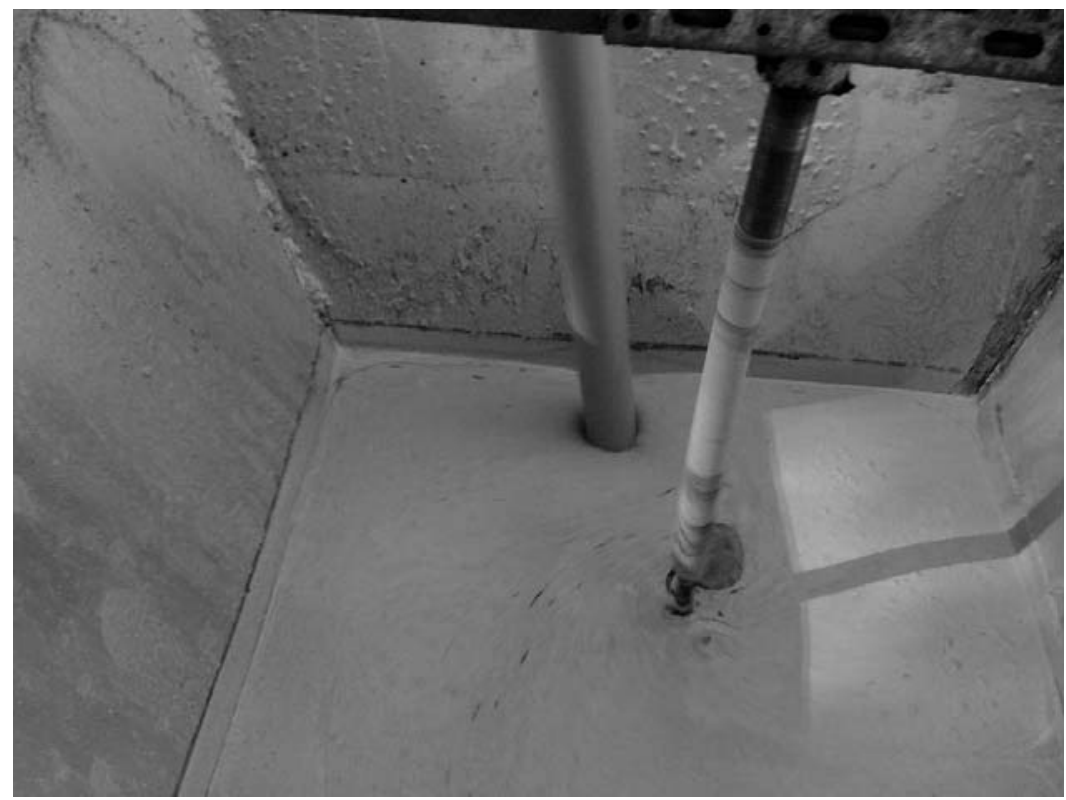

\section{Figure 10 Slurry discharging into pilot plant hopper}

The $\mathrm{C}_{\mathrm{w}}$ was determined using oven drying technique and scales with and accuracy to 0.001 grams.

$$
C_{W}=\frac{W_{W}}{W_{W}+W_{s}}
$$

Where:

$\mathrm{C}_{\mathrm{w}} \quad=\quad$ concentration by weight $(\%)$.

$\mathrm{W}_{\mathrm{s}} \quad=\quad$ weight of solids $(\mathrm{g})$.

$\mathrm{W}_{\mathrm{w}} \quad=\quad$ weight of water $(\mathrm{g})$.

\section{Data}

Figure 11 shows the pressure difference between pressure transmitters which demonstrate the pumping characteristics of the Bredel SPX hose pump. The dashed lines indicate the pressure used in the calculation for the shear stresses at shear rates from 45.63 to $194.37 \mathrm{~s}^{-1}$. Figure 12 and 13 is a graph a position A and B on Figure 11. 


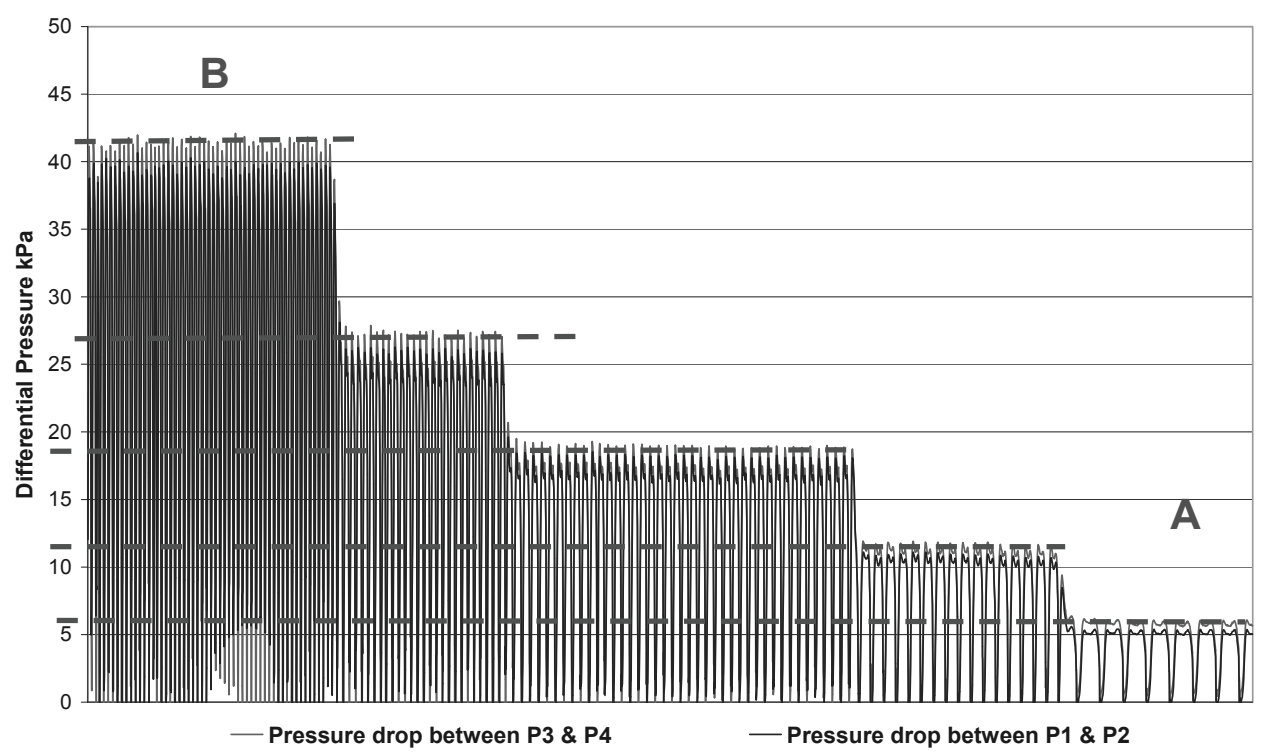

Figure 11 Pressure between the pressure transmitters

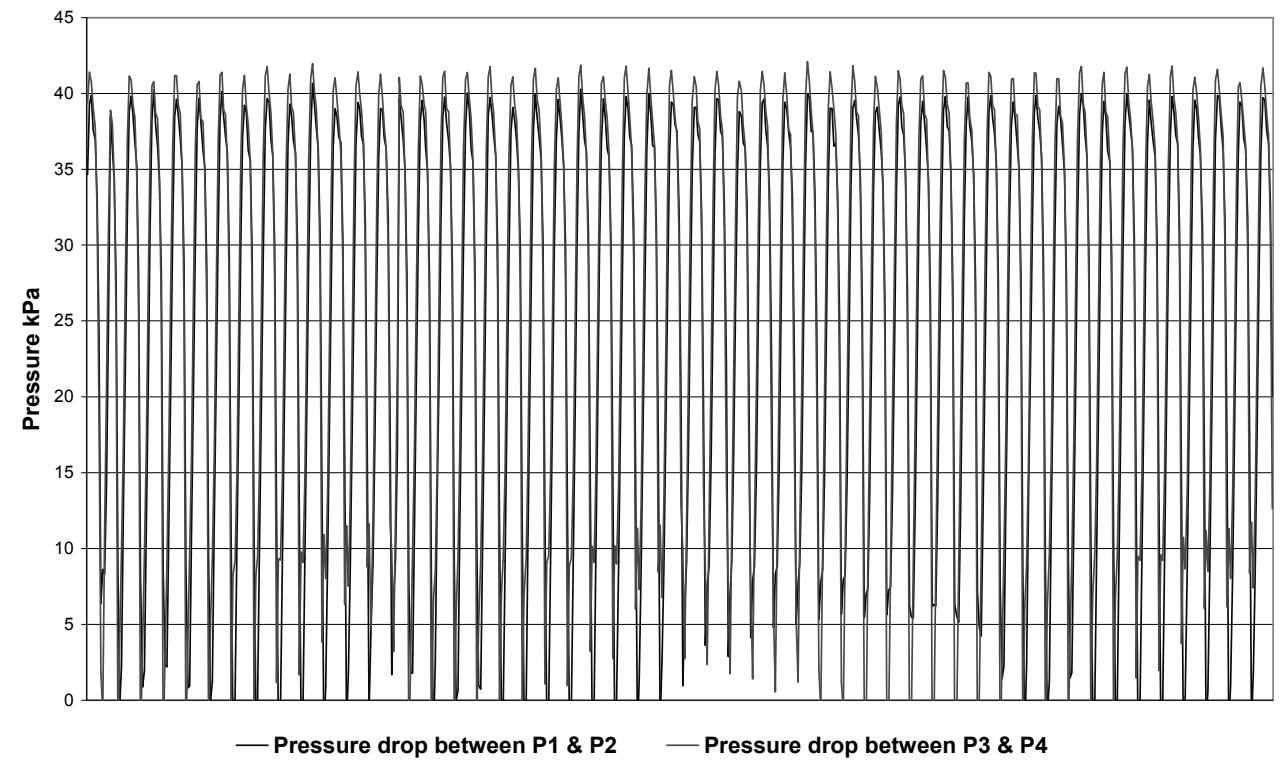

Figure 12 Pressure between at point ' $B$ ' on Figure 13 


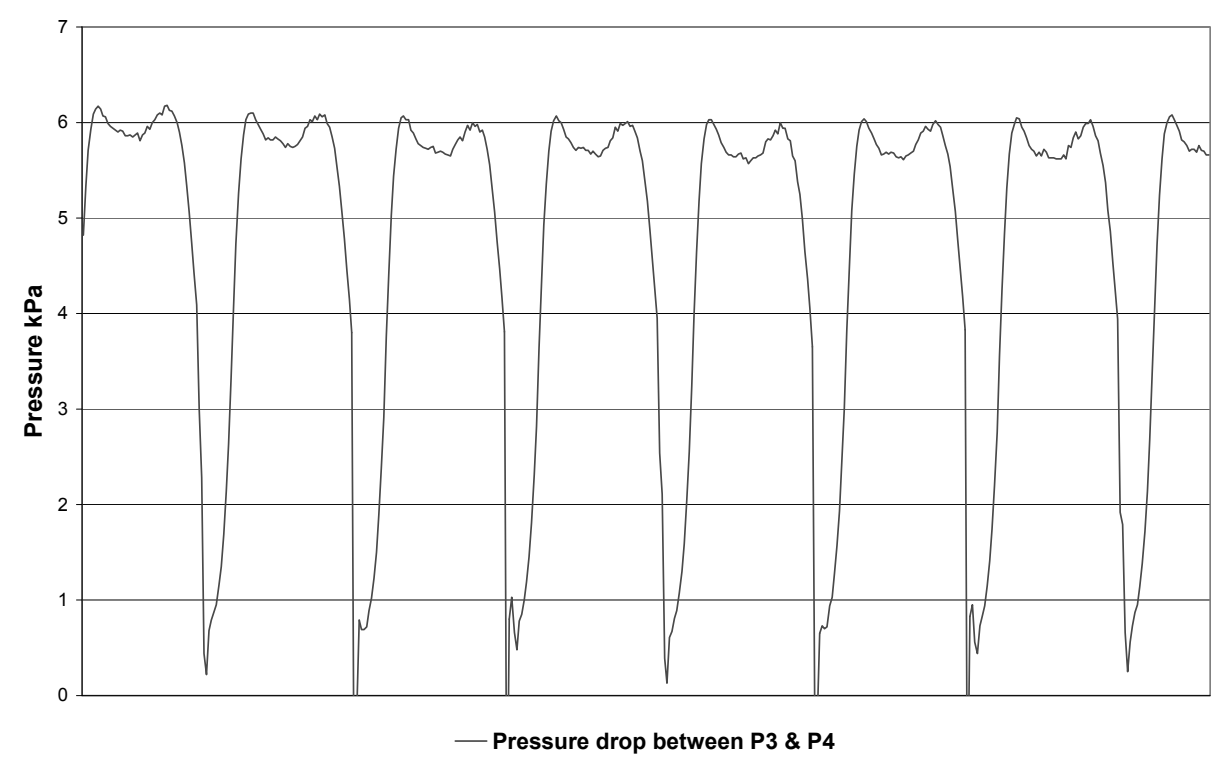

Figure 13 Pressure between at point 'A' on Figure 13

\section{Results}

The $\mathrm{d}_{50}$ of the fly ash was $40 \mu \mathrm{m}$ and of the bottom ash was $300 \mu \mathrm{m}$. The solids density of the fly ash varied from 1.7675 to $1.8558 \mathrm{tm}^{3}$ and the solids density of the bottom ash varied from 1.8535 to $1.8660 \mathrm{tm}^{3}$. Table 5 is a table of the flow diagram results.

\section{Table 5 Flow diagram results}

\begin{tabular}{llllll}
\hline Shear Rate s-1 & \multicolumn{5}{l}{ Shear Stress Pa } \\
\hline 46 & 19.66 & 15.98 & 14.75 & 13.52 & 13.52 \\
78 & 41.79 & 33.18 & 27.04 & 26.55 & 24.58 \\
117 & 73.74 & 54.07 & 46.70 & 41.79 & 39.33 \\
156 & 120.44 & 82.34 & 66.36 & 61.45 & 56.53 \\
194 & 196.64 & 130.27 & 100.78 & 89.72 & 86.03 \\
FA:BA Ratio & 3.55 & 3.55 & 3.55 & 3.35 & 3.35 \\
$\mathrm{C}_{\mathrm{w}}$ & 0.71 & 0.68 & 0.68 & 0.65 & 0.64 \\
\hline
\end{tabular}

Figures 14 is a rheogram of the fly ash slurry tested with the rotary viscometer. Figure 15 is a flow diagram of the pumping trials conducted with fly ash and bottom ash slurry.

The rheogram of the fly ash slurry as determined by the rotary viscometer and the flow diagram of the fly ash and bottom ash slurry obtained from the pilot pumping plant indicates the pumpability of the slurry at different $C_{w}$ 's. 


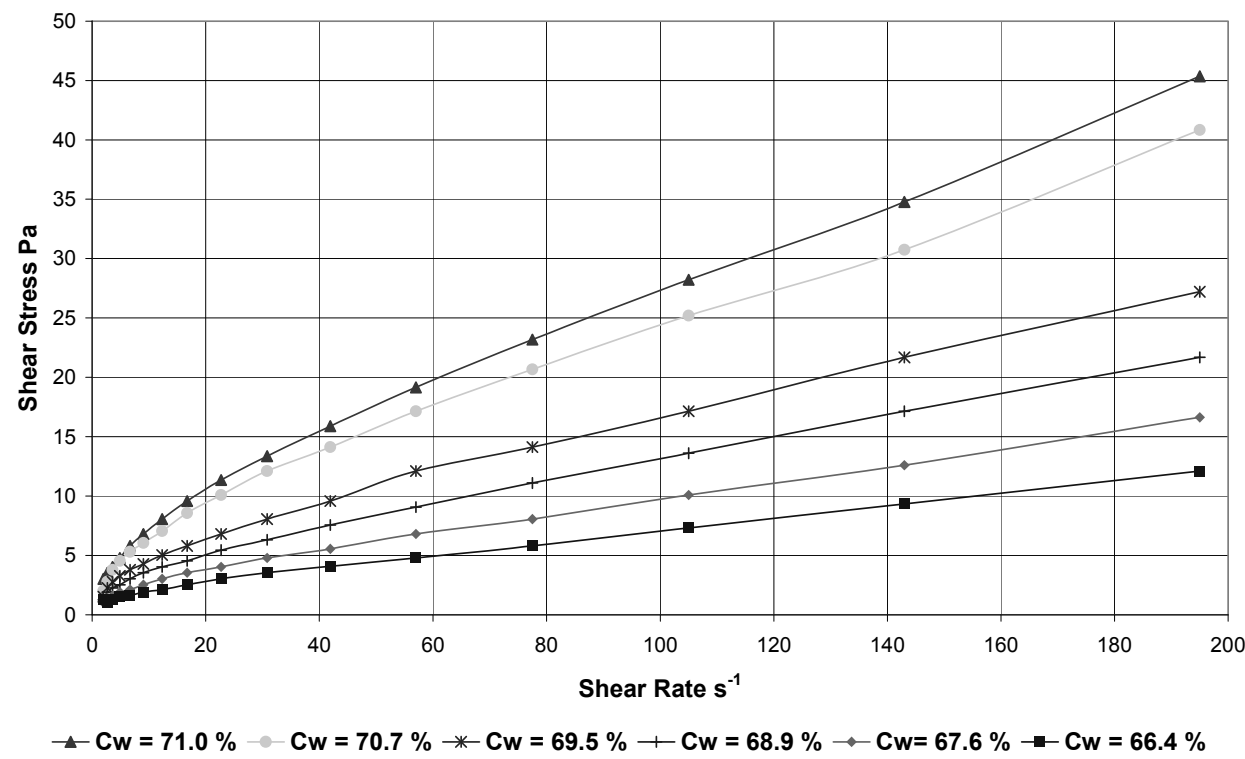

Figure 14 Shear diagram from rotary viscometer test



\section{Figure 15 Flow diagram for fly ash and bottom ash slurry}

\section{Conclusions}

The SEM Photographs indicates the lack diversity of fly ash particles sizes that is there a lack of intermediate sized particles between the larger and smaller particles. To enable the pumping of slurries at high concentration the void spaces between different particles has to filled with particles therefore you require a diversity of different size particles.

The velocity of the proposed pipeline was $1.57 \mathrm{~ms}^{-1}$. The calculated pseudo shear rate of proposed high concentrated slurry disposal was $84 \mathrm{~s}^{-1}$.

In the proposed pumping system with a maximum pipeline operating pressure of $3.5 \mathrm{MPa}$ the shear stress was calculated to be $26 \mathrm{~Pa}$.

On examining the rheogram developed from the rotary viscometer testing at a shear rate of $84 \mathrm{~s}^{-1}$ and a shear stress of $26 \mathrm{~Pa}$ the rheogram indicated that fly ash could be pumped with a $\mathrm{C}_{\mathrm{w}}$ in excess of $71 \%$. 
Examining the flow diagram developed from the pilot pumping plant at a shear rate of $84 \mathrm{~s}^{-1}$ and a pseudo shear stress of $26 \mathrm{~Pa}$ the flow diagram indicated that a the maximum $\mathrm{C}_{\mathrm{w}}$ of a mixture ratio of fly ash to bottom ash of both $85: 15$ or $80: 20$ was $64 \%$.

The explanation for this is that the fly ash and fly ash and bottom ash slurries are heterogeneous slurries therefore the rotary viscometer underestimated the pumpability of the slurry as rotary viscometers are only accurate when the slurry is homogenous.

This again leads to the discussion how do we determine if a slurry is homogenous or heterogeneous.

\section{Acknowledgements}

This research was supported by the Centre for Bulk Solids and Particulate Technologies and TUNRA Bulk Solids, The University of Newcastle, Australia. The authors gratefully acknowledge their support.

\section{References}

Bunn, T.F. (1991) The Dense Phase Hydraulic Conveying of Power Station Ash, Research Thesis, Master of Engineering, Department of Mechanical Engineering, University of Newcastle.

Ward, A., Bunn, T.F. and Chambers, A.J. (1999) The Bayswater fly ash transportation system', International Journal of Coal preparation and Utilization, Vol. 21, pp. 125-147. 
